\title{
STRATEGI KOMUNIKASI WISATA TAMAN AIR MANCUR SRI BADUGA SITU BULEUD KABUPATEN PURWAKARTA
}

\author{
Anisya Wulandari ${ }^{1)}$, Itca Istia Wahyuni ${ }^{2)}$ \\ 1) Program Studi Ilmu Komunikasi Universitas Telkom \\ ${ }^{2)}$ Program Studi Ilmu Komunikasi Universitas Telkom \\ Email ; ${ }^{1)}$ wulandarianisya@ gmail.com, ${ }^{2)}$ cha.istia@gmail.com
}

\begin{abstract}
This research was motivated by Situ Buleud is not so well known to the public then was built and developed into a Sri Baduga Fountain Park requires communication to the target audience to come to Purwakarta District. This research uses qualitative research methodology with qualitative descriptive approach. The purpose of this research is to describe and analyze the communication strategy of Sri Baduga Situ Buleud Fountain Park. The object of this research is communication strategy of DISPORAPARBUD and DISKOMINFO Purwakarta District. This session will discuss about five stage of communication plans are research, plan, execute, measure, and report. The result found that research which has been done by DISPORAPARBUD are observation and the evaluation result of the number of tourists and DISKOMINFO take the data from the monitoring media report. DISPORAPARBUD and DISKOMINFO Purwakata District has been planned to determine the source or communicator, message, media, target, and effects. The execute stage will be performed after getting approval from Purwakarta Regent by implementing the plan that has been designed. In this Measure stage, DISPORAPARBUD will count the total of tourist, while tourism media will be monitored by DISKOMINFO Purwakarta district. Report undertaken by DISPORAPARBUD Purwakarta District, conduct an evaluation by counting the number of tourists in each week and will be made a report at the end of each year. Therefor DISKOMINFO Reporting as a book report on the results of analysis from third parties
\end{abstract}

Keywords: Communication Strategy, Sri Baduga Fountain Park, Communication Planning

\section{PENDAHULUAN}

Indonesia memiliki kekayaan alam dan budayanya menjadikan potensi wisata di Indonesia cukup tinggi. Potensi wisata Indonesia yang berlimpah harus dikelola dengan optimal oleh pemerintah maupun pihak - pihak di sekitar objek wisata tersebut, sehingga menjadikan Indonesia sebagai salah satu destinasi wisata lokal maupun mancanegara. Keunikan dan ciri khas yang dimiliki oleh masing-masing wisata yang ada di Indonesia menjadi daya tarik tersendiri bagi para wisatawan yang berkunjung. Salah satu tujuan wisata yang diminati adalah wisata yang berada di Kabupaten Purwakarta, Jawa Barat.

Purwakarta memiliki 47 objek wisata yang dapat dikunjungi oleh wisatawan nusantara maupun macanegara. Jenis objek wisata terdiri dari wisata alam, sejarah, religi, dan buatan. Berdasarkan Data objek dan daya tarik wisata yang banyak dikunjungi wisatawan Dinas Pemuda, Olahraga, Pariwisata, dan Kebudayaan Kabupaten Purwakarta pada tahun 2016 wisata Taman Air Mancur Sri Baduga Situ Buleud menjadi objek wisata yang paling banyak dikunjungi wisatawan sebanyak 240.080 yang terdiri dari 
80 Wisatawan Mancanegara dan 240.000 Wisatawan Nusantara. Pada tahun sebelumnya 2014 dan 2015 objek wisata Grama Tirta Jatiluhur menjadi objek wisata paling banyak dikunjungi wisatawan sebanyak 182.554 wisatawan pada tahun 2014 dan meningkat pada tahun 2015 sebanyak 183.712 wisatawan. (Sumber: Dinas Pemuda, Olahraga, Pariwisata, dan Kebudayaan Kabupaten Purwakarta Tahun 2016).

Berdasarkan hasil data pengamatan jumlah wisatawan Kabupaten Purwakarta DISPORAPARBUD Kabupaten Purwakarta, jumlah kunjungan wisatawan nusantara maupun mancanegara yang berkunjung ke Taman Air Mancur Sri Baduga Situ Buleud dari tahun 2016 cukup tinggi dan menggantikan posisi objek wisata Grama Tirta Jatiluhur dimana pada tahun 2015 Grama Tirta Jatiluhur menduduki sebagai objek wisata yang memiliki wisatawan terbanyak di Kabupaten Purwakarta. Hal ini tidak lepas dari keindahan yang diberikan oleh air mancur taman sribaduga situ buleud. Taman Air Mancur Sri Baduga Situ Buleud ini menjadi ikon destinasi baru kabupaten Purwakarta yang memiliki air mancur yang berwarnawarni yang mengikuti alunan lagu yang diputar, dan menjadikan Patung Sri Baduga menjadi ikon objek wisata ini.

$$
\text { Menteri Pariwisata Arief Yahya }
$$
menjelaskan Taman Air Mancur Sri Baduga merupakan taman air mancur termegah dan terindah se Asia Tenggara dan masuk kedalam top five destinasi terbaik di Indonesia. Taman Air Mancur Sri Baduga Situ Buleud merupakan pengembangan dari Situ Buleud yang mulai dibangun sejak 2013. Pembangunan Air Mancur Taman Sri Baduga Situ Buleud dilakukan 3 tahap. Pembangunan tahap pertama pada tahun 2014, tahap kedua pada tahun 2015, dan tahap ketiga pada tahun 2016.

Situ Buleud merupakam ciri khas Kabupaten Purwakarta, berada di tengahtengah kota dengan latar belakang Gedung Karesidenan (saat ini menjadi Kantor Badan Koordinasi Wilayah IV Purwakarta). Situ Buleud itu sendiri merupakan sebuah danau yang berbentuk bulat yang sudah ada sejak jaman dahulu dan dibenahi untuk kepentingan pemerintah dan masyarakat Purwakarta pada tahun 1930 oleh RA Suriawinata yang merupakan pendiri Kabupaten Purwakarta. Taman Air Mancur Sri Baduga Situ Buleud merupakan wisata yang baru diresmikan pada tanggal 6 Januari 2017 oleh Menteri Pariwisata Arief Yahya bersama Bupati Purwakarta H. Dedi Mulyadi. Wisata ini memiliki luas lebih dari dua hektar yang menyuguhkan pertunjukan air mancur dengan menggunakan tekhnologi canggih dan unsur seni.

Taman Air Mancur Sri Baduga Situ Buleud menjunjung tinggi nilai kebudayaan. Taman Air Mancur Sri Baduga Situ Buleud 
mencerminkan budaya sunda dan bhineka tunggal ika. Bhineka tunggal ika tercerminkan dari warna warni air mancur tersebut. Wisata ini mengangkat Prabu Siliwangi yang biasa disebut Sri Baduga Maharaja sebagai ikon air mancur tersebut, karena Prabu Siliwangi merupakan seorang raja yang berasal dari tanah sunda yang membangun kepemimpinannya melalui nilai kasih sayang. Menurut Dedi Mulyadi sebagai Bupati Purwakarta menjelaskan Prabu Siliwangi adalah spiritnya orang sunda. Siliwangi adalah peletak dasar sistem beradat kehidupan masyarakat di tanah Sunda.

Berdasarkan dari hasil wawancara dengan Bapak Acep Yulimulya selaku Kepala Seksi Promosi dan Pengembangan Produk Wisata Dinas Pemuda, Olahraga, Pariwisata, dan Kebudayaan Kabupaten Purwakarta menjelaskan bahwa pada saat objek wisata Situ Buleud belum di bangun menjadi Taman Air Mancur Sri Baduga, Situ Buleud kurang dikenal masyarakat Indonesia, khususnya masyarakat diluar Kabupaten Purwakarta. Pada saat itu, Situ Buleud digunakan sebagai tempat sarana atraksi dalam berbagai kegiatan terutama yang berkaitan dengan ekstra kurikuler sekolah di Purwakarta, pemancingan, kontes burung, pentas seni, dan sarana olahraga massal berupa jogging dan lari pagi mengelilingi Situ Buleud. Taman Air Mancur Sri Baduga sudah dibuka untuk umum pada awal tahun 2016. Dinas Pemuda, Olahraga,
Pariwisata, dan Kebudayaan Kabupaten Purwakarta menggunakan strategi komunikasi untuk meningkatkan kunjungan wisatawan Taman Air Mancur Sri Baduga Situ Buleud. (Sumber : Hasil wawancara peneliti dengan Acep Yulimulya pada 3 Oktober 2017

Wisata Air Mancur Taman Sri Baduga Situ Buleud apabila dikelola dengan optimal oleh pemerintah maupun pihak - pihak sekitar objek wisata tersebut akan membantu meningkatkan kunjungan wisatawan ke Kabupaten Purwakarta. Untuk meningkatkan kunjungan wisatawan objek Taman Air Mancur Sri Baduga Situ Buleud memerlukan upaya seperti mengomunikasikan wisata Taman Air Mancur Sri Baduga Situ Buleud untuk membujuk dan mempengaruhi perilaku masyarakat untuk mengunjungi objek wisata tersebut. Strategi komunikasi yang baik dapat meningkatkan minat wisatawan pada objek pariwisata. Menurut Cangara, (2013:63) Strategi komunikasi adalah kiat atau taktik yang bisa dilakukan dalam melaksanakan perencanaan komunikasi. Strategi komunikasi menjadi penting karena komunikasi yang intensif dan tepat, makna yang disampaikan dapat tersampaikan secara tepat pula

Berdasarkan hal ini, maka penelitian ini dimaksudkan untuk mengetahui strategi komunikasi yang dilakukan oleh Dinas Pemuda, Olahraga, Pariwisata, dan Kebudayaan Kabupaten Purwakarta dalam mengomunikasikan wisatawan di objek wisata 
Air Mancur Taman Sri Baduga Situ Buleud. Berdasarkan latar belakang penelitian dan fokus penelitian di atas, adapun rumusan masalahnya adalah menganalisis strategi komunikasi apa yang dilakukan oleh Dinas Pemuda, Olahraga, Pariwisata, dan Kebudayaan Kabupaten Purwakarta terhadap objek wisata Taman Air Mancur Sri Baduga Situ Buleud. Adapun tujuan yang ingin dicapai dalam penelitian ini adalah untuk mengetahui dan menganalisis strategi komunikasi yang dilakukan DISPORAPARBUD Kabupaten Purwakarta dalam meningkatkan minat wisatawan di objek wisata Taman Air Mancur Sri Baduga Situ Buleud.

\section{METODE PENELITIAN}

Penelitian ini menggunakan strategi dalam menyelesaikan suatu fenomena. Penelitian strategi komunikasi wisata Taman Air Mancur Sri Baduga Situ Buleud Kabupaten Purwakarta ini menggunakan paradigma konstruktivisme. Menurut Elvinaro dan Bambang (2009: 154) Konstruktivisme adalah salah satu filsafat pengetahuan yang menekankan bahwa pengetahuan kita adalah konstruksi (bentukan) kita sendiri (Von Glasersfeld dalam Bettencourt, 1989 dan Matthews 1994).

Penelitian ini menggunakan metode kualitatif dengan wawancara mendalam kepada narasumber yang terlibat langsung dalam penyusunan dan pembuatan strategi komunikasi. Menurut Sugiyono (2016:3) Metode kualitatif digunakan untuk mendapatkan data yang mendalam, suatu data yang mendukung makna. Wawancara ini juga melibatkan ahli dalam bidang strategi komunikasi dan pihak yang menjadi target audiens dari strategi komunikasi. Metode ini menghasilkan penemuan data atau informasi yang tidak dapat dicapai dengan menggunakan prosedur kuantitatif. Subjek dari penelitian ini adalah pihak - pihak bagian Dinas Pemuda, Olahraga, Pariwisata, dan Kebudayaan Kabupaten Purwakarta dan pihak lain yang memiliki wewenang dalam pembuatan strategi komunikasi objek wisata Taman Air Mancur Sri Baduga Situ Buleud. Objek dalam penelitian ini adalah strategi komunikasi. Waktu penelitian dari bulan September hingga Januari, untuk lokasi penelitian dilakukan di Dinas Pemuda, Olahraga, Pariwisata, dan Kebudayaan Kabupaten Purwakarta Jl. Veteran No.1, Ciseureuh, Kec. Purwakarta, Kabupaten Purwakarta, Jawa Barat, 41118.

\section{HASIL DAN PEMBAHASAN}

\section{Hasil}

Peneliti akan memaparkan hasil temuan yang peneliti dapatkan selama melakukan penelitian. Hasil temuan tersebut dideskripsikan sesuai dengan fokus dan indentifikasi penelitian, yaitu mengenai strategi komunikasi serta tahapan-tahapan dalam strategi komunikasi, dimana hasil 
penelitian dikemukakan berdasarkan wawancara mendalam dengan informan yang memiliki kriteria sesuai dengan yang dibutuhkan dalam penelitian.

Penerapan strategi merupakan langkah krusial yang memerlukan penanganan secara hati-hati dalam setiap program komunikasi. Strategi komunikasi adalah kiat atau taktik yang bisa dilakukan dalam melaksanakan perencanaan komunikasi. Konsep strategi komunikasi diletakan sebagai bagian dari perencanaan komunikasi dalam mencapai tujuan yang ingin dicapai. Dalam penelitian ini penulis akan menganalisa tahapan dalam strategi komunikasi kedalam sub bab hasil penelitian dan pembahasan.

Tahapan Strategi Komunikasi wisata Taman Air Mancur Sri Baduga Situ Buleud Kabupaten Purwakarta

Dalam Cangara (2013:72), Strategi komunikasi adalah kiat atau taktik yang bisa dilakukan dalam melaksanakan perencanaan komunikasi. Penelitian ini menggunakan model perencanaan komunikasi lima langkah yang terdiri atas lima tahapan yaitu Research, Plan, Execute, Measure, dan Report. Penulis akan menjabarkan lima tahapan model perencanaan komunikasi lima langkah yang digunakan dalam strategi komunikasi wisata Taman Air Mancur Sri Baduga Kabupaten Purwakarta sebagai berikut:

\section{a. Penelitian (Research)}

Informan satu menambahkan mengenai riset strategi komunikasi Taman Air Mancur Sri Baduga Situ Buleud yang dilakukan DISPORAPARBUD:

"Sebenarnya untuk riset kita belum pernah mengadakan secara khusus. Kita hanya melakukan observasi saja, melihat bahwa Purwakarta perlu mempunyai ikon, dan kami ingin meningkatkan jumlah wisatawan ke Purwakarta, dengan cara mengomunikasikan ke masyarakat, Situ Buleud ini berada di tengah pusat Kota Purwakarta. Kita pun melakukan riset secara tidak resmi seperti melakukan evaluasi dari setiap pertunjukan. Kita juga mengambil data dari hasil laporan untuk dijadikan bahan pertimbangan untuk melakukan rencana komunikasi selanjutnya. Untuk melihat perkembangan rumor di masyarakat di media ada dari DISKOMINFO. DISKOMINFO ada dari pihak ketiga untuk melihat media-media... sebelum melakukan perancangan kita bekerja sama dengan DISKOMINFO menyiapkan bahan-bahan seperti konten yang akan digunakan, seperti logo, dan medianya. diserahkan ke bapak bupati dulu, untuk disetujui keputusan dari bupati... Strategi komunikasinya dulu sepertinya tidak menggunakan banyak media hanya media cetak buku panduan wisata, sehingga tidak ada banyak wisatawan datang ke sini ke Situ Buleud ke Purwakarta., Hanya dulu Taman Air Mancur ini merupakan sebuah Situ Buleud yang sepi pengunjung yang diubah menjadi Taman Air Mancur yang cantik, diharapkan banyak wisatawan datang. Dan juga hanya karna purwakarta kota kecil hanya kota pensiuanan. Kita mencoba lepas dari jargon itu. Kita harus unggul istimewa dengan tidak meninggalkan budaya sunda,... observasi dilakukan sebelum tahun 2014 dilakukan tim pembangunan Bupati,.. data laporan untuk riset dilihat dari bulan Desember pada 
tahun sebelumnya tahun $2016, .$. meskipun data observasi sudah dari sebelum tahun 2014 tetap melihat nilai nilai yang ingin dikembangkan dan dilihat ke masyarakat seperti mengangkat tokoh sri baduga go international sampai sekarang, media monitoring menyesuaikan perkembangan masyarakat apa yang perlu diperbaiki disetiap bulannya, jumlah wisatawan dilihat bagaimana terus meningkatkan jumlah wisatawan " (Hasil wawancara dengan Acep Yulimulya 7 Desember 2017)

Informan dua menjelaskan mengenai riset yang dilakukan DISKOMINFO terkait Taman Air Mancur Sri Baduga Situ Buleud:

"Kita pakai data hasil laporan dari pihak ketiga untuk dijadikan bahan strategi komunikasi selanjutnya. Kita juga fokus memuat konten dari data tujuan Purwakarta, lebih kearah sunda, kenapa menggunakan Sri Baduga karena Sri Baduga merupakan raja dari kerajaan Sunda, Purwakarta ingin mengangkat budaya sunda... data yang dilihat setiap bulan karena untuk melihat respon di masyarakat pada bulan sebelumnya,.. mengolah data laporan media monitoring membutuhkan 2 hari dari laporan yang sudah diterima dan kami analisis" (Hasil Wawancara dengan Ajat Sudrajat 7 Desember 2017)

\section{Informan ketiga mengungkapkan}

dalam menentukan reseach itu menggunakan dua sumber data, ada yang sifat sekunder ada yang bersifat primer. Data primer yaitu berupa data survei atau analisis situasi. Sedangkan untuk data sekunder yaitu menggunakan media analisis, yang pada umumnya digunakan ketika kondisi kritis atau tidak memiliki cukup waktu untuk melakukan survei langsung.
"Kalo secara garis besar research itu biasanya menggunakan dua sumber data, ada yang bersifat data sekunder ada yang data primer,kalo dia perusahaan itu mempunyai banyak waktu maka dia biasanya menggunakan data primer bisa deciding survey misalnya kalo kerja di biro iklan maka sebelum iklan itu kemunculan produk bisanya melakukan evciding melakukan survei melakukan tadi research atau analisis situasi atau kalo punya waktu yang nggak mencukupi ketika krisis umpamanya terkait kecelakan pesawat nggak mungkin survey dulu, dia bisa melakukan data sekunder, data sekunder sekarang bisa digunakan dua ada yang pakai social media analisi ada yang menggunkan media analisis itu sumbernya,... kalau data yang didapatkan sudah bagus, ada observasi langsung dan ada juga dari pihak ketiga." (Hasil wawancara dengan Tito Edy Priandono 18 Desember 2017)

\section{b. Perencanaan (Plan)}

Informan satu menjelaskan untuk menentukan komunikator, isi pesan, media, target sasaran, dan efek yang diharapkan.

"Strategi komunikasi dilakukan dengan berbagai macam media, supaya bisa mengkomunikasikan ke masyarakat bahwa Taman Air Mancur Situ Buleud ini ada di Purwakarta dan wajib dikunjungi... kalau komunikator seperti pembicara dari pemkab itu Bapak Bupati karena Bapak yang berwenang.... Ingin pesan-pesan yang mempengaruhi masyarakat luas... Iya ada key messagenya, Taman Air Mancur Terbesar Seasia Tenggara, Air Mancur Situ Buleud luas hampir 5 hektar, dan sudah di setujui KEMENPAR... Mengenai foto cover header di media sosial resmi milik Kabupaten Purwakarta menggunakan foto Air mancur sri baduga karena landmark dari kabupaten, jadi digunakan semua foto air mancur sri baduga... Media massa, cetak dan internet ya. Di media Youtube, Twitter, Facebook, Path, Instagram, 
diskominfo berperan penting dalam pengelolaan media-media... Semua masyarakat dan warga luar negeri karna air mancur wisata untuk semua umur dan semua kalangan... untuk semua kalangan atas menengah bawah karena tempat hiburan gratis,.. Kalau efek diharapkan menarik minat wisatawan, Taman Air Mancur ini air mancur terbesar di Asia Tenggara, semoga setelah terpapar langsung timbul keinginan lanjut bergerak untuk datang ke Purwakarta. Tidak menutup kemungkinan ada wisatawan membuka bisnis, seperti hotel gantung,... Pak dedi sudah direncanakan semenjak bangun Taman Air Mancur tahun 2014 sampai saat ini selalu bupati purwakarta yang direncanakan menjadi komunikator, pesan, target sasaran dan efek yang dirancang ini sudah dari tahun 2015 sebelum dibuka untuk umum, namun untuk media menggunakan twitter, facebook, Instagram, youtube dari 2015. " (Hasil wawancara dengan Acep Yulimulya 7 Desember 2017)

Informan dua menjelaskan mengenai

perencanaan komunikasi seperti menentukan sumber atau komunikator, isi pesan, media, target sasaran, dan efek yang diharapkan:

"Peran Bapak Bupati pasti, Karena Bapak yang memiliki gagasan.,... key message Air Mancur terbesar se Asia Tenggara, dimasukan kedalam isi pesannya, ... Konten yang dibuat video, foto, berita,... Untuk konten kita tetep ada budaya Sundanya, logo Pesona Sunda Purwakarta cuma dikemas lebih modern, sok diliat lah hasil video editing editing nya seperti apa,... Untuk proses pembentukan konten kalau masalah ide, kita tim juga sharing, berita release juga kita buat lalu diserahkan ke media-media cetak dan media online, cuma kalau yang punya gagasan-gagasan hebat itu yang dari pak Bupati, kalau kayak misalnya gambar, audio, video, sampai tampilan website sama sosmed, kita pengen video Air Mancur Sri Baduga yang bagus, bikin sok yang bagus mana, ada kira-kira dikirim 10 ke pak Bupati, misalnya "saya suka yang ini cuma ditambahin ini ya" tetep, yang punya gagasan Bapak, yang bikin dari tim, nah kembali lagi ke pak Bupati, nah jadilah logo yang bener-bener kita inginkan.... kita pakai semua media, Selain kita juga punya website, trus media social facebook, twitter, Instagram, berita release itu melalui media cetak media elektronik yang media cetak nya kita bekerjasama dengan media koran majalah diantaranya sindo kompas media indonesia koran lokal karawang express pasundan express. Kemudian kita juga berkerja sama dengan media online yaitu kompas.com headline jabar Purwakarta News, Kabar Cirebon, Pikiran Rakyat, Republika, Okezone, Metro TV News .... Target audience seluruh masyarakat, bahkan warga luar negeri, untuk semua kalangan apalagi gratis kalangan menengah kebawah bisa datang... Mudah mudahan setelah melihat dan mendengar hasilnya masyarakat punya harapan bersyukur punya pimpinan yang bagus komitmen tentang pembangunan Purwakarta dan ramai wisatawan datang ke air mancur,..." (Hasil Wawancara dengan Ajat Sudrajat 7 Desember 2017)

Informan ketiga menjelaskan mengenai perencanaan komunikasi:

"Semua penting atuh kalo dalam komunikasi dapat persuaisi merubah orang itu biasanya orang yang terpapar itu percaya jadi saya mau datang ke sri baduga saya terpersuaisi. persuasi kan itu ada dua alur maksudnya kesan tempatnya bagus, saya suka tempatnya berkesan tapi ada juga yang ke sri baduga karna ada komunikator nya kalau... Isi pesan ada key message nya ya bagus atuh itu, membuat mereka mau datang, jadi pembeda juga. Saya juga pernah mendengar di berita koran key message seperti slogan wisata air mancur sri baduga nya. Sudah bagus... Target audience itu juga harus ditetapkan, kalau untuk seluruh masyarakat umum ya 
disesuaikan konten pesannya, supaya efek nya sesuai apa yang diharapkan " (Hasil wawancara dengan Tito Edy Priandono 18 Desember 2017)

\section{c. Pelaksanaan (Execute)}

Informan satu menjelaskan mengenai tindakan yang dilakukan setelah melakukan perancangan komunikasi:

"Perencanaan yang sudah dibuat diberikan ke Bapak Bupati, untuk mendapat persetujuan, setelah mendapat persetujuan baru kita jalankan ... Untuk sumber atau komunikator Bapak Bupati pasti.. iya pakai taman air mancur terbesar se Asia Tenggara, ada di caption keterangan dari foto atau video nya... seluruh media sosial pemkab yang sering digunakan Twitter, Facebook Instagram, untuk share informasi dan reminding untuk datang ke pertunjukan Taman Air Mancur Sri Baduga... konten yang digunakan gambar dan video... ya dengan media yang digunakan untuk menjangkau target sasaran dan tujuan nya agar mereka datang kesini,.. Pak Dedi dari tahun 2016 sudah menjadi komunikator, key messagesudah digunakan dari 2016 sampai saat ini,.. unsur-unsur konten yang dilakukan 3 hari sebelum jadwal upload, uploadnya kamis sampai sabtu pagi" (Hasil wawancara dengan Acep Yulimulya 7 Desember 2017)

Informan dua menjelaskan mengenai tindakan yang diambil untuk menjalankan perencanaan komunikasi yang telah dibuat:

"Komunikatornya Pak Dedi karena untuk melakukan ini harus atas persetujuan bapak, ... kita tetap pakai air mancur terbesar seasia tenggara, supaya masyarakat terus ingat dan sadar ini taman air terbesar seasia tenggara ada di Purwakarta lho... kalau youtube langsung dibuatkan videonya. Tinggal dilakukan saja sesuai prosedurnya, ingin dijadikan berita ya buat beritanya dulu, berita release nya yang sudah di berikan ke beberapa media, nah ambil satu berita release nya ini yang kekeringan situ buleud taman air mancur ditutup sementara, ternyata yang angkat berita ini ada 7 media dari yang udah direncanakan ada merdeka.com, Bandung.bisnis.com, Pikiran Rakyat, Ayo Purwakarta, Media Indonesia, Sindo News, Okezone,...kalau poin-poin untuk kontennya air mancur sri baduga ada pesan air mancur sri baduga di setiap keterangan foto gambar video, nah di gambar dan video ada logo Pesona Sunda,... oh ya yang ini budaya Sunda nya terlihat dari bangunannya, yaitu patung Sri Baduga, lebih fokus untuk ngajak masyarakat untuk datang,tapi ada logo pesona sunda... media sosial yang digunakan twitter facebook Instagram, kalau youtube jarang, karena nunggu ada acara dan membuat konsep dulu... ya sesuai dengan target sasaran, banyak yang datang itu keluarga, bersama teman-teman, yang berpasangan, lebih banyak yang bawa keluarga,... untuk publish ke media sosial seminggu sekali sekitar hari kamis sampai sabtu pagi,.. pesan dan konten bersamaan dengan postingan itu. " (Hasil wawancara dengan Ajat Sudrajat 7 Desember 2017)

Informan ketiga menjelaskan mengenai pelaksanaan dari perencanaan komunikasi yang baik:

"Yang ingin disampaikan dimedia itu sesuai sama yang di rancang. Intinya implementasi dari perencanaan." (Hasil wawancara dengan Tito Edy Priandono 18 Desember 2017)

\section{d. Pengukuran (Measure)}

Informan satu mengenai indikator penilaian yang digunakan oleh

\section{DISPORAPARBUD:}

"Dilihat dari jumlah pengunjung saja, hasil akhirnya banyaknya pengunjung, Purwakarta semakin rame, cara mengukur jumlah wisatawan Ada checker yang 
mengitung penonton manual, membuka dan menutup setiap pintu... Ya melebihi target sasaran malah karna dilihat dari pengunjung yang data ada dari luar jawa, awal diperkirakan hanya 5.000, ternyata hampir disetiap malam minggu yang datang bisa sampai 20.000, ini untuk dua kali sesi pertunjukan dengan kondisi padat.... . Kalau media monitoring dari diskominfo supaya tau masyarakat lagi ngomongin apa tentang berita atau informasi yang disampaikan dari Pemerintah Purwakarta,...perhitungannya itu dilakukan pas saat pertunjukannya, kemudian senin di data, dan di serahkan kepada kepala DISPORAPARBUD pada saat buku laporan diserahkan pada akhir tahun" (Hasil wawancara dengan Acep Yulimulya 7 Desember 2017).

Informan dua menjelaskan menenai indikator penilaian bahwa strategi komunikasi:

"Oh itu mah jelas, karna ngeliat dari luar juga jelas, ngeliat dari komentar juga bisa, komentar-komentar positif, bahkan efeknya bapak (Bupati) sering diundang jadi narasumber berkaitan dengan pembangunan kota, sok diliat pak Bupati sering diundang, ini loh keberhasilan salah satu Bupati yang berhasil memimpin daerahnya.... kita juga punya IMM nih dari pihak ketiga, dari konsultan, nah ini bahkan sebaran informasi sampai seluruh Indonesia kita ketauan, hari ini tanggal ini yang mengucapkan Purwakarta sampai ke Papua tentang ini. Ini monitoring nya mingguan sama bulanan. Nah ini melihat, hot issue nya apa, top issue nya apa, nah ini kan ketauan bupati purwakarta sekarang hot issue nya lagi kesini, nah ini laporannya dalam bentuk buku. Kalau buku laporannya hanya untuk DISKOMINFO... untuk menetralisisr isu negative yang berkembang ya pertama otomatis kita liat berita negatifnya apa dulu, kita bisa nge blowup berita yang positif lagi, kita kembangkan issue issue yang bagus-bagus lagi, nah selain itu kita kan mantau ini lagi, untuk menanggapi sentiment yang negative ini kita bisa langsung sidak ke tempat yang negatif ini,... Waktu memonitoringnya setiap bulan full, sudah ada teknologi nya, tinggal di kembangkan oleh pihak ketiga yang lebih ahli" (Hasil wawancara dengan Ajat Sudrajat 7 Desember 2017)

Informan ketiga menjelaskan mengenai

indikator penilaian untuk mengetahui hasil akhir dari strategi komunikasi:

"Indikatornya macam macam bisa output jumlah pemberitaan jumlah pengunjung jumlah apalagi umpama bikin event nih jumlah pengunjung berapa pengunjung nya naik ngga berita nya di recover lagi berapa berapa yang muncul di pemberitaan jadi apa apa ditanya itu output kalo income bisa macem macem saya nggak tau apakah pemda melakukan itu... Menggunakan media monitoring pihak ketiga berarti itu bagus udah melakukan tinjauan analisis" (Hasil wawancara dengan Tito Edy Priandono 18 Desember 2017)

\section{e. Pelaporan (Report)}

Informan satu menjelaskan mengenai bentuk laporan dan evaluasi dari perencanaan komunikasi:

"kalau evaluasi tiap minggu paling cuman jumlah pengunjung di rekap, dari sini hanya berupa lembaran diserahkan ke kepala DISPORAPARBUD. Dari mingguan, nanti buat laporan ditiap akhir tahunnya jumlah pengunjungnya. Dari laporan itu bisa jadi bahan untuk program komunikasi selanjutnya dilihat banyaknya pengunjung berarti apa kontennya. Untuk media laporan dari diskominfo kalau ada isu dari media atau masyarakat tentang wisata iya langsung di evaluasi dan langsung diperbaiki oleh tim diskominfo. Nah itu juga jadi bahan untuk program komunikasi selanjutnya,... akhir tahun bulan November kita jumlahkan pengunjung dari januari sampai 
November, kemudian di buat laporannya pada bulan desember yang berisi jumlah wisatawan diseluruh objek wisata di Kabupaten Purwakarta dan diserahkan pada bulan desember ke kepala DISPORAPARBUD” (Hasil wawancara dengan Acep Yulimulya 7 Desember 2017)

Informan dua menjelaskan mengenai evaluasi dan bentuk pelaporan yang dilakukan

\section{DISKOMINFO:}

"Ya dari IMM sudah memberikan evaluasi dari seluruh kegiatan di media, sudah ada analisisnya, kemudian ada tindakan untuk menanggapi isu negative, ya kita blow up yang positifnya. Bentuknya berupa buku laporan dari pihak ketiga itu... iya dijadikan untuk melakukan program komunikasi selanjutnya,... buku laporan nya lewat email, kemudian di tembus ke bapak kepala diskominfo, langsung pada akhir pekan itu itu"

Informan ketiga menjelaskan mengenai bentuk pelaporan yang baik untuk strategi komunikasi:

"Buku laporan, tidak selalu berupa buku cetak, jaman sekarang serba online dan canggih, jadi bisa aja bentuknya softfile, tergantung setiap institusi. Dari tahap pengukuran tadi dari pihak ketiga itu sudah bagus, ada buku laporannya. Yang pasti ukuran atau tujuan dari perusahaan tercapai tidaknya, bagaimana citra institusi apakah positif negatif." (Hasil wawancara dengan Tito Edy Priandono 18 Desember 2017)

\section{Pembahasan}

Pada tahun 2014, Situ Buleud mulai dibangun tahap satu dan dikembangkan menjadi sebuah Taman Air Mancur Sri Baduga untuk meningkatkan wisatawan datang ke Purwakarta. Taman Air Mancur Sri Baduga
Situ Buleud mulai dibuka untuk umum pada awal tahun 2016 pada pembangunan tahap ketiga yang diresmikan pada awal tahun 2017. Dalam pembuatan strategi komunikasi Dinas Pemuda, Olahraga, Pariwisata dan Kebudayaan Kabupaten Purwakarta bersama dengan Dinas Komunikasi dan Informasi Kabupaten Purwakarta membuat dan mengumpulkan data yang akan digunakan untuk melakukan perancangan komunikasi. Pada Sub-bab ini, penulis menganalisa strategi komunikasi wisata Taman Air Mancur Sri Baduga Situ Buleud berdasarkan unit analisis dan fokus penelitian yaitu dengan melihat tahapan-tahapan yang digunakan dalam strategi komunikasi. Pada bagian ini peneliti akan membahas mengenai analisa hasil dari penelitian yang telah dilakukan melalui wawancara mendalam dengan dua informan utama dan seorang informan ahli. Hal ini bertujuan untuk memberikan informasi berdasarkan data yang telah penulis peroleh.

\section{Tahapan Strategi Komunikasi wisata Taman Air Mancur Sri Baduga Situ Buleud Kabupaten Purwakarta}

\section{a. Research}

Berdasarkan pernyataan dari pihak Dinas Pemuda, Olahraga, Pariwisata dan Kebudayaan Kabupaten Purwakarta melakukan observasi dengan melihat kondisi Kabupaten Purwakarta yang perlu memiki icon dan ingin mengomunikasikan wisata Taman Air Mancur Sri Baduga Situ Buleud 
kepada masyarakat untuk datang ke wisata Taman Air Mancur Sri Baduga Situ Buleud. DISPORAPARBUD Kabupaten Purwakarta juga melihat dari hasil evaluasi dari setiap pertunjukan air mancur untuk dijadikan bahan perbaikan pertunjukan air mancur selanjutnya. DISKOMINFO Kabupaten Purwakarta menggunakan hasil laporan dari pihak ketiga untuk dijadikan bahan strategi komunikasi selanjutnya. DISKOMINFO juga melihat data dari tujuan Kabupaten Purwakarta untuk membuat konten, yaitu lebih mengarah budaya Sunda.

$$
\text { Reseach yang dilakukan }
$$

DISPORAPARBUD Kabupaten Purwakarta adalah dengan menggunakan data primer, dimana menggunakan observasi langsung dengan analisis situasi bahwa diperlukannya landmark atau icon Kabupaten Purwakarta dan ingin meningkatkan wisatawan dengan mengbangun Situ Buleud menjadi Taman Air Mancur Sri Baduga Situ Buleud. DISKOMINFO menggunakan data sekunder karena menggunakan pihak ketiga untuk memonitoring media yang sudah dilakukan dalam melakukan strategi komunikasi.

\section{b. Perencanaan (Plan)}

Setelah mengetahui tahapan research, Dinas Pemuda, Olahraga, Pariwisata dan Kebudayaan Kabupaten Purwakarta mengambil tindakan untuk menggunakan berbagai macam media, agar tercapai masyarakat luas dan masyarakat mengetahui bahwa Taman Air Mancur Sri Baduga Situ Buleud merupakan objek wisata yang wajib dikunjungi. Dalam menentukan sumber atau komunikator untuk menyampaikan isi pesan, Acep Yulimulya menjelaskan bahwa komunikator atau sumber adalah Dedi Mulyadi selaku Bupati Purwakarta. DISKOMINFO juga mengatakan bahwa komunikator dari pihak Pemerintah Kabupaten Purwakarta diwakili oleh Dedi Mulyadi selaku Bupati Purwakarta. Dedi Mulyadi menjadi komunikator dalam menyampaikan komunikasi ini dikarenakan Dedi Mulyadi merupakan seseorang yang membuat gagasan dan wewenang mengenai perkembangan Kabupaten Purwakarta. Untuk sumber yang digunakan dalam perancangan komunikasi yang dilakukan Dinas Komunikasi dan Informasi, berupa sumber yang berasal dari alat rekam untuk mendapatkan video ataupun gambar yang akan dijadikan konten atau bahan untuk memuat isi dari pesan yang akan disampaikan.

\section{DISPORAPARBUD Kabupaten}

Purwakarta dan DISKOMINFO Kabupaten Purwakarta memiliki kata kunci pada pesan yang akan disampaikan yaitu "Taman Air Mancur Tebesar Se-Asia Tenggara”. Menggunakan key message itu dikarenakan luas Situ Buleud mencapai 5 hektar dan sudah mendapat persetujuan dengan Kementrian Pariwisata. Dengan kata kunci pesan tersebut, diharapkan masyarakat dapat mengingat dan 
datang ke wisata Taman Air Mancur Sri Baduga Situ Buleud.

Konten yang di buat oleh Dinas Pemuda, Olahraga, Pariwisata dan Kebudayaan Kabupaten Purwakarta bersama Dinas Komunikasi dan Informasi menggunakan konten yang dikemas lebih modern mengikuti perkembangan teknologi. Pembuatan konten seperti gambar, audio, video, dan berita, yang berisikan poin-poin seperti menunjukan budaya Sunda dan logo Purwakarta Pesona Sunda. Konten yang dibuat misalnya DISKOMINFO Kabupaten Purwakarta membuat 10 video mengenai wisata Taman Air Mancur Sri Baduga Situ Buleud, selanjutnya video-video tersebut dikirim kepada Bupati Purwakarta, kemudian Bupati memilih satu, dan memberikan masukan. Sehingga dalam pembuatan konten harus mendapat persetujuan dengan Bupati Purwakarta. DISKOMINFO membuat berita release yang salah satunya berasal dari hasil research yang berisi informasi untuk menutupi isu negative dan mengangkat isu positif.

Dalam menentukan

media, DISPORAPARBUD Kabupaten Purwakarta dan DISKOMINFO Kabupaten Purwakarta menggunakan media massa, media cetak, media online, dan media sosial seperti Youtube, Twitter, Facebook, dan Instagram. Selain itu peneliti menemukan website resmi Kabupaten Purwakarta yang berisikan informasi mengenai Kabupaten Purwakarta, termasuk objek wisata Taman Air Mancur Sri Baduga Situ Buleud. Website resmi Kabupaten Purwakarta adalah www.purwakartatourism.com. Dalam website tersebut terdapat logo media sosial resmi Kabupaten Purwakarta yang dapat di click dan langsung terhubung dengan media sosial terkait. Dinas Komunikasi dan Informasi berperan penuh dalam penggunaan media sosial. DISKOMINFO Kabupaten Purwakarta bekerjasama dengan media cetak seperti Koran Sindo, Kompas, Media Indonesia, Karawang Express, Pasundan Express. DISKOMINFO Kabupaten Purwakarta juga bekerjasama dengan media online yaitu kompas.com, Headline Jabar, Purwakarta News, Kabar Cirebon, Pikiran Rakyat,Republika,Okezone, metrotvnews.com, MediaIndonesia.com,Merdeka.com,Breakingn ews.co.id, Purwakartapost.co.id, dan Ayopurwakarta.com.

Dinas Pemuda, Olahraga, Pariwisata dan Kebudayaan Kabupaten Purwakarta berharap dari perencanaan komunikasi ini akan memberikan efek yaitu dapat menginformasikan ke target sasaran dan target sasaran datang ke Taman Air Mancur Sri Baduga. Dengan isi pesan "Taman Air Mancur terbesar Se-Asia Tenggara" dan menggunakan berbagai macam media agar dapat menarik minat wisatawan, dan menimbulkan minat untuk membuka bisnis di Kabupaten Purwakarta. Dinas Komunikasi dan Informasi juga berharap efek yang akan dihasilkan dapat 
membuat masyarakat melihat dan bersyukur mempunyai pimpinan yang berkomitmen untuk membangun Kabupaten Purwakarta.

\section{c. Pelaksanaan (Execute)}

Tindakan yang diambil sebagai bentuk implementasi dari perencanaan yang telah dibuat oleh Dinas Pemuda, Olahraga, Pariwisata dan Kebudayaan Kabupaten Purwakarta dan Dinas Komunikasi dan Informasi akan dijalankan setelah mendapat persetujuan dengan Bupati Purwakarta, Dedi Mulyadi. Dedi Mulyadi tetap menjadi komunikator atau sumber. Menurut Acep Yulimulya dan Ajat Sudrajat, Dedi Mulyadi memiliki wewenang dan memiliki gagasan terhadap Taman Air Mancur Sri Baduga Situ Buleud, kemudian perencanaan komunikasi pun dibuat atas persetujuan Dedi Mulyadi. Key Message "Taman Air Mancur Sri Baduga Situ Buleud" yang telah di rencanakan diterapkan pada konten-konten yang dibuat oleh DISKOMINFO Kabupaten Purwakarta. Konten yang dilaksanakan yaitu berupa gambar, video, dan berita. Salah satu konten video yang dibagikan di media sosial Instagram yang dilakukan oleh DISKOMINFO Kabupaten Purwakarta menggunakan logo pesona sunda dan menunjukan budaya Sunda dari patung Sri Baduga dan patung harimau.

Sri Baduga atau yang lebih dikenal dengan Prabu Siliwangi merupakan Seorang raja dari Kerajaan Sunda dan memiliki legenda dengan harimau di tanah Sunda. Dalam video tersebut menunjukan pertunjukan Taman Air Mancur Sri Baduga Situ Buleud. Key Message ada berada di caption atau deskripsi pada konten video tersebut.

\section{Berita yang dibuat DISKOMINFO} Kabupaten Purwakarta pun tetap dilakukan, salah satu berita release yang sudah dilakukan DISKOMINFO Kabupaten Purwakarta yang berjudul "Debit Air Berkurang, Air Mancur Sri Baduga Tutup Sementara" setelah diberikan kepada media online yang sudah bekerjasama dengan DISKOMINFO Kabupaten Purwakarta, terdapat tujuh media yang me-release berita tersebut, diantaranya Merdeka.com, Bandung.bisnis.com, Breakingnews.co.id, Pikiran Rakyat, Ayopurwakarta.com, Media Indonesia, Sindo News, dan Okezone.com.

Media yang digunakan yaitu Instagram, Facebook, dan Twitter. Peneliti melihat dari media-media tersebut cukup aktif dalam memposting konten yang telah dibuat oleh DISKOMINFO Kabupaten Purwakarta. Konten dan media yang dilakukan untuk menjangkau target sasaran dan untuk mencapai tujuan perencanaan komunikasi, yaitu target sasaran datang ke Taman Air Mancur Sri Baduga Situ Buleud. Target sasaran sesuai dengan yang direncanakan, yaitu didominasi wisatawan yang membawa keluarga dan rekan-rekannya. 


\section{d. Pengukuran (Measure)}

Untuk pengukuran dari pelaksanaan komunikasi objek wisata Taman Air Mancur Sri Baduga Situ Buleud oleh Dinas Pemuda, Olahraga, Pariwisata dan Kebudayaan Kabupaten Purwakarta menggunakan indikator penilaian yang dilihat dari jumlah pengunjung yang datang disetiap pertunjukan Taman Air Mancur Sri Baduga Situ Buleud yaitu setiap malam Minggu.

Dinas Pemuda, Olahraga, Pariwisata dan Kebudayaan Kabupaten Purwakarta berkerjasama dengan Dinas Komunikasi dan Informasi untuk mengetahui isu positif maupun negatif mengenai pariwisata dan kebudayaan Kabupaten Purwakarta, salah satunya objek wisata Taman Air Mancur Sri Baduga Situ Buleud. Dinas Komunikasi dan Informasi menggunakan media monitoring dengan pihak ketiga untuk memantau kabar terkait Pemerintahan Kabupaten Purwakarta termasuk Taman Air Mancur Sri Baduga Situ Buleud diseluruh media seperti media massa, cetak, televisi, radio, dan media online. Pihak ketiga yang dipercaya oleh Dinas Komunikasi dan Informasi untuk media monitoring adalah Intelligence Media Management (IMM).

Menurut Tito Edy Priandono selaku ahli pakar komunikasi, pihak Dinas Pemuda, Olahraga, Pariwisata dan Kebudayaan Kabupaten Purwakarta dengan melakukan pengukuran terhadap jumlah pengunjung yang datang di setiap pertunjukan Taman Air
Mancur Sri Baduga Situ Buleud dan Dinas Komunikasi dan Informasi Kabupaten Purwakarta melakukan pengukuran untuk mengetahui hasil analisis dari media-media yang sudah digunakan melalui pihak ketiga dikatakan sudah baik dalam melakukan tinjauan analisis.

\section{e. Pelaporan (Report)}

Untuk tindakan terakhir dari kegiatan strategi komunikasi terhadap objek wisata Taman Air Mancur Sri Baduga Situ Buleud yang telah dilaksanakan oleh Dinas Pemuda, Olahraga, Pariwisata dan Kebudayaan Kabupaten Purwakarta yaitu dengan melakukan evaluasi dan mendata jumlah wisatawan di setiap minggunya dan dibuat sebuah laporan jumlah wisatawan di setiap tahunnya, kemudian diserahkan kepada Kepala DISPORAPARBUD Kabupaten Purwakarta. Dinas Komunikasi dan Informasi di setiap bulannya mendapatkan laporan hasil analisis mengenai media-media yang digunakan dalam perencanaan komunikasi dari pihak ketiga yaitu Intelligence Media Management (IMM). Bentuk Pelaporan dari Intelligence Media management (IMM) adalah buku laporan. Laporan dari DISPORAPARBUD dan DISKOMINFO Kabupaten Purwakarta dapat digunakan sebagai data pada tahapan research dalam program perencanaan komunikasi selanjutnya. 


\section{KESIMPULAN}

Berdasarkan hasil analisis dan pembahasan yang telah dipaparkan pada babbab sebelumnya, dapat disimpulkan bagaimana proses strategi komunikasi yang dilakukan oleh Dinas Pemuda, Olahraga, Pariwisata dan Kebudayaan serta Dinas Komunikasi dan Informasi Kabupaten Purwakarta sebagai berikut:

1) Pada tahap pertama, DISPORAPARBUD Kabupaten Purwakarta melakukan tahapan research dengan melakukan observasi langsung dan melihat hasil laporan jumlah pengunjung objek wisata Taman Air Mancur Sri Baduga Situ Buleud. Berdasarkan hasil research yang dilakukan oleh DISPORAPARBUD dan DISKOMINFO, maka diperlukan perancangan komunikasi agar masyarakat lebih mengetahui tentang objek wisata Taman Air Mancur Sri Baduga Situ Buleud.

2) Tahap selanjutnya yang dilakukan oleh DISPORAPARBUD dan DISKOMINFO Kabupaten Purwakarta yaitu dengan membuat perancangan komunikasi pada tahap plan. Tahap plan yang dilakukan oleh DISPORAPARBUD dan DISKOMINFO Kabupaten Purwakarta yaitu dengan menentukan sumber atau komunikator, pesan, konten, media, target sasaran, dan efek. DISKOMINFO dalam perencanaan komunikasi berperan penuh dalam mengolah pesan serta media yang sudah ditentuan oleh DISPORAPARBUD. Setelah membuat perancangan komunikasi, DIPORAPARBUD dan DISKOMINFO Kabupaten Purwakarta meminta persetujuan Bupati Purwakarta terkait perancangan komunikasi yang sudah dirancang, yang selanjutnya akan dilakukan tahap execute atau melaksanakan semua yang sudah dirancang pada perencanaan komunikasi.

3) Pada tahap execute, seluruh perencanaan komunikasi terlaksana sesuai dengan yang direncanakan, dimana yang bertindak selaku komunikator yaitu Dedi Mulyadi selaku Bupati Purwakarta dengan pesan yang disampaikan yaitu dengan kata kunci "Taman Air Mancur Terbesar Se-Asia Tenggara”. Kemudian konten yang dibuat yakni video yang memuat logo pesona sunda serta menunjukan budaya Sunda yang disebar melalui media Instagram. Selain itu berita release juga terlaksana dan di-release oleh tujuh media online. Dengan pelaksanaan perencanaan komunikasi tersebut, target sasaran yang diharapkan dapat tercapai.

4) Setelah melakukan tahap execute, selanjutnya yang dilakukan oleh DISPORAPARBUD dan DISKOMINFO Kabupaten Purwakarta adalah tahap measure atau pengukuran. Tahap measure yang dilakukan DISPORAPARBUD 
Kabupaten Purwakarta yaitu dengan menggunakan indikator penilaian yang dilihat berdasarkan jumlah wisatawan yang datang disetiap pertunjukan Taman Air Mancur Sri Baduga Situ Buleud, sedangkan DISKOMINFO Kabupaten Purwakarta menggunakan media monitoring dengan pihak ketiga.

5) Hasil dari measure yang dilakukan oleh DISPORAPARBUD dan DISKOMINFO yaitu berupa report atau pelaporan yang dibukukan. Report atau pelaporan yang dilakukan oleh Dinas Pemuda, Olahraga, Pariwisata dan Kebudayaan Kabupaten Purwakarta yaitu dengan melakukan evaluasi jumlah wisatawan Taman Air Mancur Sri Baduga Situ Buleud di setiap minggunya dan akan dibuat laporan disetiap akhir tahun. Laporan yang dibuat oleh DISPORAPARBUD akan diserahkan kepada Kepala DISPORAPARBUD Kabupaten Purwakarta, sedangkan pelaporan yang dilakukan oleh Dinas Komunikasi dan Informasi merupakan hasil analisis media monitoring dari pihak ketiga.

\section{DAFTAR PUSTAKA}

Ardianto, Elvinaro, \& Bambang, Q-Anees. (2009, h. 154). Filsafat Ilmu Komunikasi. Bandung: Simbiosa Rekatama Media.
Cangara, Hafied. (2013, h. 72, 63). Perencanaan \& Strategi Komunikasi. Jakarta: PT. Raja Grafindo Persada

Sugiono. (2016, h. 3). Memahami Penelitian Kualittatif. Bandung: Alfabeta.

Ispranoto, Tri. (2016, 13 Januari). Kisah Situ Buleud: Dulu Kubangan Badak Kini Jadi Taman Air Mancur Fenomenal. Diambil dari https://news.detik.com/ berita/3117367/ kisah-situ-buleuddulu-kubangan-badak-kini-menjaditaman-air-mancur-fenomenal.

Maulud, Mochammad Iqbal. (2017, 15 Oktober). Purwakarta, dari Kota Pensiun ke Kota Sejuta Impian. Diambil dari http://www.pikiranrakyat.com/jawa-barat/2017/10/15 /purwakarta-dari-kota-pensiun-ke-kotasejuta-impian-411565

Nugraha, Mega. (2016, 10 Januari). Taman Situ Buleud di Purwakarta Sudah Dibuka Untuk Umum Tiap Hari Tapi. Diambil dari http://jabar.tribunnews.com /2016/01/10/taman-situ-buleud-dipurwakarta-sudah-dibuka-untukumum-tiap-hari-tapi.

Salam, Bram. (2016, 11 Januari). Mengenal Sosok Sri Baduga, di Balik Kemegahan Air Mancur Purwakarta. Diambil dari https://www.merdeka.com/ 
peristiwa/mengenal-sosok-sri-baduga-

di-balik-kemegahan-air-mancur-

purwakarta.html. 